\title{
Fuels by Waste Plastics Using Activated Carbon, MCM-41, HZSM-5 and Their Mixture
}

\author{
Norbert Miskolczi ${ }^{1}$, Chunfei $\mathrm{Wu}^{2}$, Paul T. Williams ${ }^{3}$ \\ ${ }^{1}$ Chemical Engineering and Process Engineering Institute, MOL Department of Hydrocarbon and Coal Processing, University of Pannonia, \\ Veszprém, 10 Egyetem u., 8200, Hungary \\ ${ }^{2}$ Energy Research Institute, University of Leeds, Leeds, LS2 9JT, UK \\ ${ }^{3}$ School of Engineering, University of Hull, Hull, HU6 7RX, UK
}

\begin{abstract}
Waste material was pyrolyzed in a horizontal tubular reactor at $530-540^{\circ} \mathrm{C}$ using different catalysts, such as activated carbon, MCM-41, HZSM-5 and their mixtures. Products were investigated by gas-chromatography, EDXRFS and standardized methods. Catalysts significantly affected the yields of volatiles; e.g. HZSM-5 catalyst increased especially the yield of gaseous hydrocarbons, while MCM-41 catalyst was responsible for increasing the pyrolysis oil yield. Synergistic effects were found using mixtures of different catalysts. Furthermore the catalysts modified the main carbon frame of the products. Pyrolysis oil obtained over HZSM-5 catalyst contained large amounts of aromatics, while MCM-41 catalyst mainly isomerized the carbon frame. Regarding contaminants it was concluded, that the sulphur content could be significantly decreased by activated carbon, however it had only a slight effect to the other properties of the products.
\end{abstract}

\section{Introduction}

Pyrolysis has benefits not only by reducing the huge mass of polymer wastes, but also enormous energy could be saved by chemical recycling. During pyrolysis, the polymer macromolecules decompose into gaseous and liquid products, which have lots of similarities with commercial fuel gas, naphtha or even gas oil. In general, 400-1000 ${ }^{\circ} \mathrm{C}$ is used for waste depolymerization depending on the technologies (using batch reactor, tubular reactor, fluidized bed, rotary kiln, etc.) [1-5]. Higher temperature promotes the formation of gaseous hydrocarbons, coke deposits, and the products contain lots of cyclic hydrocarbons or aromatics. Aliphatic hydrocarbons (both saturated and unsaturated) are the main products using lower pyrolysis temperatures $\left(<600^{\circ} \mathrm{C}\right)$ [4-9]. The product yields and composition are affected also by the application of catalysts, which could increase the yield of volatiles (both gases and pyrolysis oils) [10-14]. It was demonstrated, that the structure of zeolites had a key role in relation to the product properties. E.g. mainly alkanes are produced over yzeolite, while unsaturated hydrocarbons and aromatics are the main fractions using ZSM-5 [4, 10, 11, 16].

Based on references, the energetic application of pyrolysis product is the mostly investigated way for their further utilization $[15,17]$. However there are different alternatives for further product utilization, depending on the pyrolysis parameters (Figure 1).

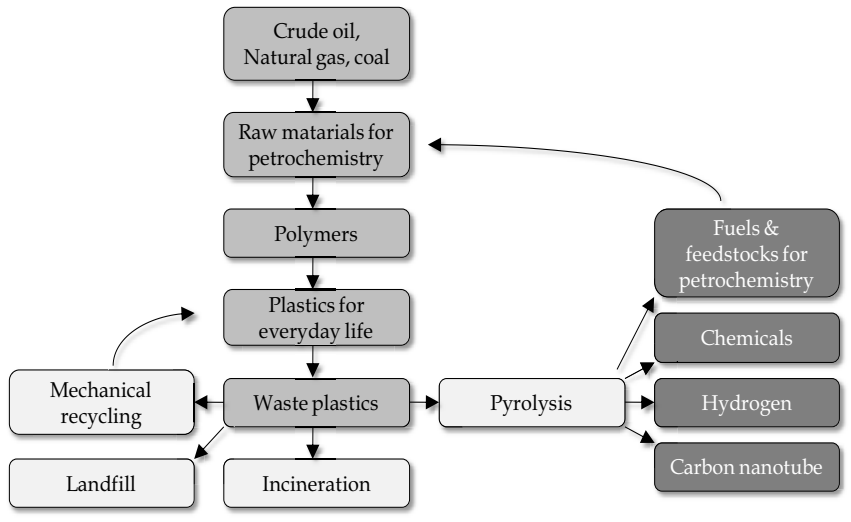

Figure 1. Ways for utilizations of pyrolysis products obtained by waste plastic

Not only fuels, but also different other valuable products could be generated: chemicals, hydrogen, olefin rich fractions for petrochemical application, carbon nanotube, carbon black, etc. Hydrogen rich gas is the main product, using metal containing catalyst and high temperature, while olefin rich fraction and other chemicals are the main products using catalyst with high $\mathrm{Si} / \mathrm{Al}$ ratio. Carbon nanotube production also requires special catalyst and elevated temperature. It is important to remark that corrosion and emission problems could occur when contaminated pyrolysis products are further used. Therefore the decreasing of contaminants in products is a real problem [9]. 
In this work thermo-catalytic pyrolysis of waste low density polyethylene and high density polyethylene was investigated in a horizontal tubular reactor at $530-540^{\circ} \mathrm{C}$ using activated carbon, MCM-41 and HZSM-5 catalysts and their mixtures. Especially the effect of catalysts and their mixtures to the product yield and composition was investigated.

\section{Material and methods}

\subsection{Raw materials}

Mixture of real waste high density polyethylene (HDPE) and low density polyethylene (LDPE) from packaging was used in this work. According to preliminary analysis, raw material contained $74.8 \%$ HDPE and 15.2\% LDPE. The main properties of the raw materials are summarized in Table 1.

Table 1. The main properties of real waste plastics

\begin{tabular}{|l|l|}
\hline Property & Value \\
\hline Average particle size, $\mathrm{mm}$ & $3-4$ \\
\hline Proximate analysis & \\
\hline Ash content, \% & 2.9 \\
\hline Volatile content, \% & 1.4 \\
\hline Combustible, $\%$ & 95.7 \\
\hline Ultimate analysis & \\
\hline $\mathrm{C}, \%$ & 85.71 \\
\hline $\mathrm{H}, \%$ & 14.21 \\
\hline $\mathrm{Cl}, \%$ & 0.05 \\
\hline $\mathrm{S}, \%$ & 0.02 \\
\hline
\end{tabular}

Samples of average particle size of $3-4 \mathrm{~mm}$ were used. Owing to the real waste source, raw material had contamination, in the form of chlorine $(0.05 \%)$ and sulfur $(0.02 \%)$, while the moisture and ash content were $1.4 \%$ and $2.9 \%$, respectively.

In order to modify the yield and composition of products, different catalysts and their mixtures were tested: activated carbon, MCM-41 and HZSM-5. Table 2 demonstrates the composition of catalyst mixtures.

Table 2. The composition of catalysts (in \%)

\begin{tabular}{|l|l|l|l|}
\hline Catalyst & Activated carbon & MCM-41 & HZSM-5 \\
\hline C-1 & 100 & - & - \\
\hline C-2 & - & 100 & - \\
\hline C-3 & - & - & 100 \\
\hline C-4 & 50 & 50 & - \\
\hline C-5 & 50 & - & 50 \\
\hline C-6 & - & 50 & 50 \\
\hline C-7 & 33.33 & 33.33 & 33.33 \\
\hline
\end{tabular}

The main properties of catalysts are summarized in Table 3. Catalysts had similar grain size, in the range between 10 and $109 \mathrm{~m}$. MCM-41 had higher Si/Al ratio than HZSM-5, while its acidity was lower. Activated carbon and MCM-41 catalyst had the highest BET surface area with $859 \mathrm{~m}^{2} / \mathrm{g}$ and $824 \mathrm{~m}^{2} / \mathrm{g}$, respectively.
Table 3. The properties of catalysts

\begin{tabular}{|l|l|l|l|}
\hline & $\begin{array}{l}\text { Activated } \\
\text { carbon }\end{array}$ & MCM-41 & $\begin{array}{l}\text { HZSM- } \\
\mathbf{5}\end{array}$ \\
\hline Grain size, m & $10-109$ & $15-84$ & $10-79$ \\
\hline $\mathrm{Si} / \mathrm{Al}$ ratio & - & 40 & 25 \\
\hline $\begin{array}{l}\text { Acidity, mequiv of } \\
\mathrm{NH}_{3} / \mathrm{g}\end{array}$ & - & 0.15 & 0.60 \\
\hline $\mathrm{BET}$ area, $\mathrm{m}^{2} / \mathrm{g}$ & 859 & 824 & 298 \\
\hline
\end{tabular}

\subsection{Apparatus for waste plastic pyrolysis}

A horizontal tubular reactor was used for waste plastic pyrolysis. Waste plastics were ground to particles of 3$4 \mathrm{~mm}$ before the pyrolysis. A hopper was filled with the plastic in the first section of the electrically heated extruder. The feed rate was $2 \mathrm{~kg}$ hourly. The molten waste raw material was directly fed into the reactor stage from the extruder end section, where it was suddenly heated to $530-540^{\circ} \mathrm{C}$. Waste HDPE and LDPE were decomposed into smaller hydrocarbon molecules in the reactor. The mixtures of decomposed hydrocarbons were separated into gases, pyrolysis oil and heavy oil in a distillation column connected to the end section of reactor. Gases from the top section of the distillation column were condensed in a water cooled tubular heat exchanger, and then a given ratio of the condensed product (pyrolysis oil) was driven back to the distillation unit top section. Higher efficiency of distillation could be reached by this procedure. The bottom temperature of the separation unit was set $300-350^{\circ} \mathrm{C}$. Temperatures were controlled by PID controllers in all of the technology. In case of thermocatalytic pyrolysis $4 \mathrm{wt} \%$ of catalysts were added into the raw material. Products were collected and further analyzed.

\subsection{Methods}

Gases and pyrolysis oil were analyzed by DANI gaschromatograph using FID. For gas analysis $50 \mathrm{~m} \times 0.32$ mm fused silica column with $\mathrm{Al}_{2} \mathrm{O}_{3} / \mathrm{KCl}$ coating was used and the temperature was constant $40^{\circ} \mathrm{C}$ during the analysis. In case of pyrolysis oil analysis, $30 \mathrm{~m} \times 0.32 \mathrm{~mm}$ Rtx ${ }^{\circledR}-1$ column was used. The temperature was elevated from $40^{\circ} \mathrm{C}$ to $330^{\circ} \mathrm{C}$ with $15^{\circ} \mathrm{C} / \mathrm{min}$ ramp, and then the temperature was kept constant for 10 minutes.

The concentrations of sulphur and chlorine were measured by a PHILLIPS PW 4025/02 (MiniPal) EDXRF spectrometer, which was fitted with a rhodiumside window tube anode (power of $9 \mathrm{~W}$ ) and Si-PIN detector.

Volatile characteristic of pyrolysis oil was also determined by Engler distillation test to measure the volume of hydrocarbon distilled at given temperatures (ASTM-D 1078).

\section{Results and discussion}

\subsection{Product yields}


Product yields are summarized in Figure 2, which shows significant differences among quantities of gases, pyrolysis oil and heavy oil in the presence of catalysts and their mixtures.

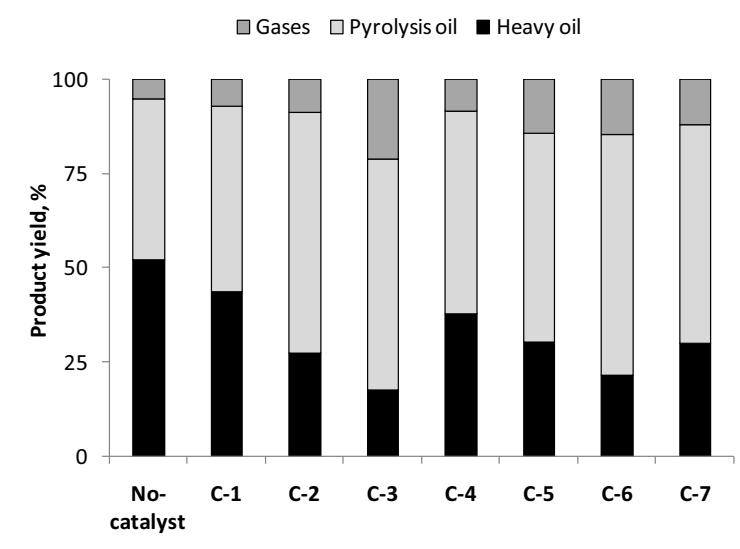

Figure 2. Product yields using different catalysts.

Pyrolysis of waste polymers resulted in $42.7 \%$ pyrolysis oil and $5.1 \%$ gases without catalyst, which did not change significantly using activated carbon, because the yields of gases and pyrolysis oil were only increased to $7.2 \%$ and $49.2 \%$. Results demonstrated that the activated carbon had only a very slight catalytic effect. The increase in yields of volatiles rather could be attributed to the larger heat transmission area, which was due to the high BET surface area of activated carbon.

The increase in volatile yields was well shown using MCM-41 or HZSM-5 catalysts. HZSM-5 significantly increased the yields of gaseous product $(21.1 \%)$, while $63.9 \%$ and $61.4 \%$ pyrolsis oil yield was observed using MCM-41 and HZSM-5 catalysts, respectively. Regarding the catalyst mixtures it could be concluded, that the adding of activated carbon only slightly deteriorated the advantageous properties of both MCM-41 and HZSM-5 to the pyrolysis oil yield increasing. Furthermore nearly the highest $(63.7 \%)$ yield of pyrolysis oil was obtained from waste pyrolysis over 50\%/50\% MCM-41/HZSM-5 catalysts. MCM-41 catalyst had larger pore size than HZSM-5; therefore it has catalytic activity rather in pyrolysis oil increasing, while HZSM-5 catalyst with smaller pores efficiently could increase the yields of gaseous products.

\subsection{Gases}

The compositions of gaseous products are summarized in Tables 4/a and 4/b. Based on GC analysis, it is clear that the gaseous fraction contained methane, ethane and ethene, propene and propane, butane and butene, iso- $\mathrm{C} 4$, pentene and pentane, iso-C5 hydrocarbons. Without catalyst, the concentrations of before listed components were $13.5 \%, 29.9 \%, 22.8 \%, 28.6 \%, 3.4 \%$ and $0.9 \%$, respectively. It means that mainly the $\mathrm{C}_{2}, \mathrm{C}_{3}$ and $\mathrm{C}_{4}$ hydrocarbons represented the most dominant fractions in the gases. Similar result was found in case of catalysts; however notable isomerisation of the main carbon frame was also demonstrated. Especially the iso-C4 concentration could be increased; it was $11.7 \%$ and $16.6 \%$ using MCM-41 and HZSM-5 catalysts respectively. It is important to remark, that the application of activated carbon did not affect significantly the concentration of components in the gases.

Table 4/a. Composition of gases obtained by waste plastic pyrolysis at $530-540^{\circ} \mathrm{C}$, in vol $\%$.

\begin{tabular}{|l|r|r|r|r|}
\hline Catalyst & No-catalyst & \multicolumn{1}{c|}{ C-1 } & \multicolumn{1}{c|}{ C-2 } & \multicolumn{1}{c|}{ C-3 } \\
\hline Methane & 13.5 & 16.9 & 14.3 & 22.3 \\
\hline Ethene, Ethane & 26.9 & 25.6 & 21.7 & 17.0 \\
\hline Propene, Propane & 22.8 & 20.7 & 22.8 & 15.0 \\
\hline Butene, Butane & 28.6 & 28.4 & 18.2 & 18.8 \\
\hline iso-C4 & 3.4 & 2.8 & 11.7 & 16.6 \\
\hline Pentene, Pentane & 4.0 & 4.2 & 5.1 & 4.3 \\
\hline iso-C5 & 0.9 & 1.5 & 6.3 & 6.0 \\
\hline
\end{tabular}

Regarding catalysts mixtures, it could be concluded, that only a slightly less effect of catalysts were found using $50 \%$ activated carbon and $50 \%$ MCM- 41 , or $50 \%$ activated carbon and $50 \%$ HZSM-5, than it was demonstrated in the case of MCM-41 and HZSM-5 catalysts. E.g. the iso-C4 content was $11.1 \%$ and $15.4 \%$ over $50 \%$ activated carbon and $50 \%$ MCM- 41 , or $50 \%$ activated carbon and 50\% HZSM-5, respectively. Similar result was found regarding iso-C5 compounds, because it was increased from $0.9 \%$ (without catalyst) to $1.5 \%$ (activated carbon) - 6.3\% (MCM-41). Regarding the gaseous fraction the HZSM-5 catalyst had a more significant isomerisation effect, than MCM-41 catalyst, which could be attributed to its BET area. The main frame of instable molecule fragments could be isomerized in the propagation reaction step resulting in high concentration of branched molecules.

Table 4/b. Composition of gases obtained by waste plastic pyrolysis at $530-540^{\circ} \mathrm{C}$, in vol\%. (cont.)

\begin{tabular}{|l|r|r|r|r|}
\hline Catalyst & \multicolumn{1}{|c|}{ C-4 } & \multicolumn{1}{c|}{ C-5 } & \multicolumn{1}{c|}{ C-6 } & \multicolumn{1}{c|}{ C-7 } \\
\hline Methane & 13.6 & 19.8 & 16.1 & 13.7 \\
\hline Ethene, Ethane & 20.8 & 21.0 & 19.6 & 23.1 \\
\hline Propene, Propane & 19.6 & 16.4 & 20.6 & 21.3 \\
\hline Butene, Butane & 25.6 & 21.0 & 18.8 & 17.0 \\
\hline iso-C4 & 11.1 & 15.4 & 13.8 & 13.0 \\
\hline Pentene, Pentane & 3.8 & 3.7 & 4.9 & 6.3 \\
\hline iso-C5 & 5.5 & 2.7 & 6.2 & 5.6 \\
\hline
\end{tabular}

\subsection{Pyrolysis oil}

Pyrolysis oils were analyzed by gas-chromatography to know more about their composition. Based on the results it was concluded, that $\mathrm{C}_{5}-\mathrm{C}_{34}$ hydrocarbons were represented in the pyrolysis oils. The composition of pyrolysis oils as function of carbon atoms are shown in Figure 3. Owing to the structure of HDPE and LDPE, two well separated peaks were appeared in gas chromatograms belong to each carbon atoms. The statistical distribution of compounds concentration as function of carbon atoms is also characteristic of 
polyethylene degradation. The structure of polyethylene is relative stable, because it contains mainly secondary carbon atoms, therefore the distortion of the electron cloud and the parts with structural faults are relatively low.

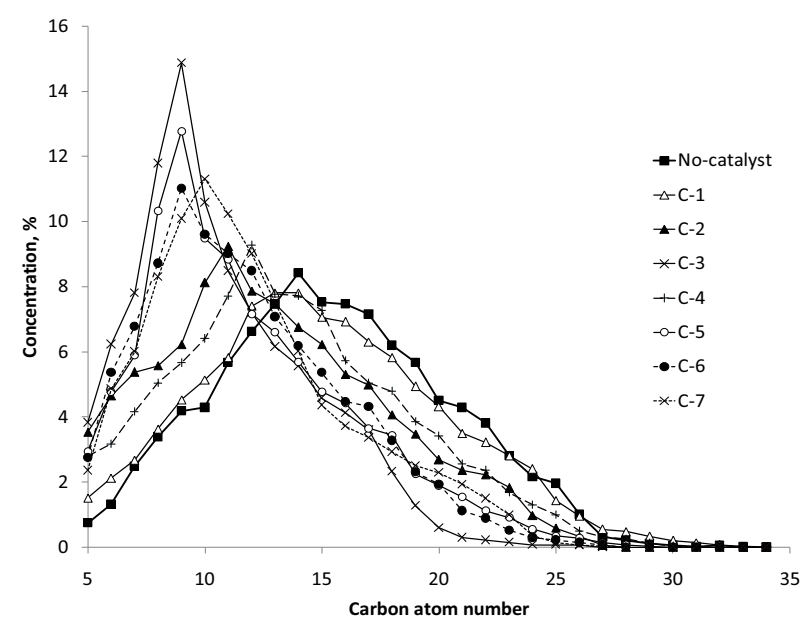

Figure 3. Distribution of compounds in pyrolysis oil as function of carbon atoms.

Regarding thermal pyrolysis without catalyst, compounds with carbon atoms of 14 had the highest concentration $(8.43 \%)$. The application of activated carbon did not change notably the distribution curve, because e.g. the maximum point also belongs to carbon atoms of $14(7.82 \%)$. However both MCM-41 and HZSM-5 catalysts had a significant effect on the product distribution: e.g. the maximum points were shifted to carbon atoms of $11(9.02 \%)$ and $9(14.88 \%)$ using MCM41 and HZSM-5 catalysts, respectively. Regarding HZSM-5 catalyst, the high aromatic portion of pyrolysis oil was the cause for the high value of $\mathrm{C}_{9}$ compounds.

Significant increases in compounds with shorter chain $\left(<\mathrm{C}_{14}\right)$ was found using both MCM-41 and HZSM-5 catalysts, while the concentration of larger molecules $\left(>C_{14}\right)$ decreased in those cases. That was the cause for the average molecular weight decreasing using both MCM-41 and HZSM-5 catalysts (Figure 4). As the data show the average molecular weight of pyrolysis oil was $242 \mathrm{~g} / \mathrm{mol}$ without catalyst, while it could be significantly decreased by both MCM-41 (178g/mol) and HZSM-5 $(139 \mathrm{~g} / \mathrm{mol})$ catalysts, while it could be only slightly decreased by activated carbon $(235 \mathrm{~g} / \mathrm{mol})$. Regarding the mixtures of catalysts, the $50 \% / 50 \%$ HZSM-5 and activated carbon mixture have shown also a significant effect resulting in molecular weight decrease $(142 \mathrm{~g} / \mathrm{mol})$.

Figure 5 shows the composition of pyrolysis oils, which contain non-branched, branched alkanes and aromatic hydrocarbons. Results well demonstrate the isomerisation and aromatization effect of catalysts. E.g. pyrolysis oil contained $89.2 \%$ non-branched and $10.8 \%$ branched hydrocarbons without catalyst. The concentration of branched hydrocarbon increased to $31.9 \%$ and $35.5 \%$ by the using of MCM-41 and HZSM-5 catalysts.

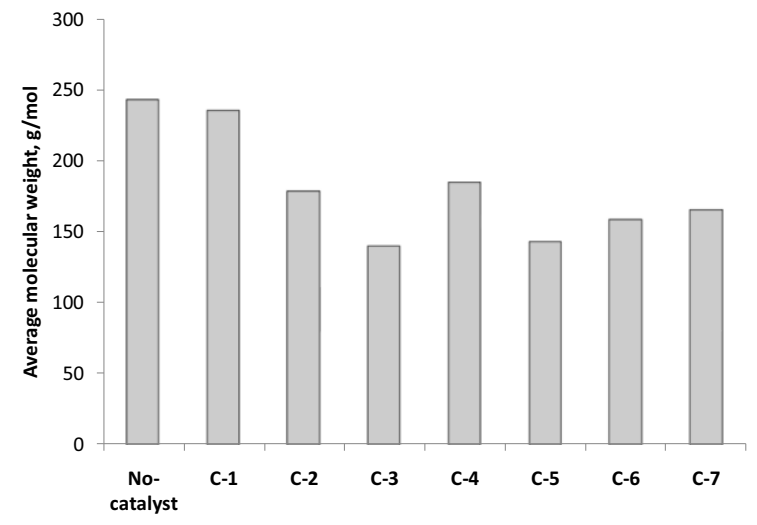

Figure 4. Calculated average molecular weights of pyrolysis oil.

Regarding aromatics, the HZSM-5 catalyst showed the highest activity, because the concentration of aromatic hydrocarbons reached $34.1 \%$ using HZSM-5. This result was confirmed by earlier work, when the high activity of HZSM-5 catalyst to the aromatization reactions was concluded $[4,10,11,16]$. It is also clear, that activated carbon could not increase the aromatic content in pyrolysis oil. MCM-41 catalyst rather had an effect to the isomerisation reactions, which resulted in an elevated concentration of branched compounds. Regarding the application of catalyst mixtures, aromatization and isomerisation effect was found in the presence of HZSM5 catalyst.

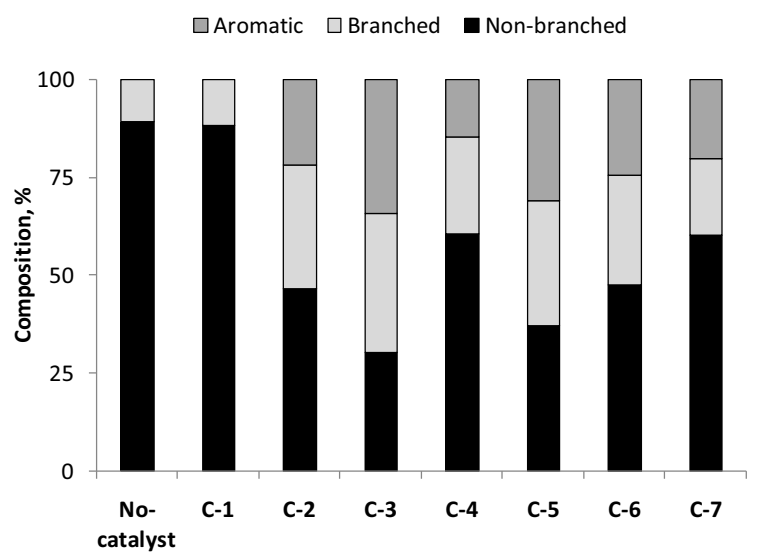

Figure 5. Composition of pyrolysis oils.

The composition of aromatics in pyrolysis oils are summarized in Figure 6. Pyrolysis oils contain benzene, toluene, ethyl-benzene, styrene, xylenes, isopropylbenzene, a-methyl styrene, cumene and other aromatic hydrocarbons. According to the results, over HZSM-5 catalyst (C-3) significant values of ethyl-benzene, styrene and xylenes were measured; $17.12 \%, 19.67 \%$ and $16.33 \%$, respectively. MCM-41 catalyst (C-2) has also aromatization function; because the total aromatic concentration was $21.6 \%$ using that catalyst. 


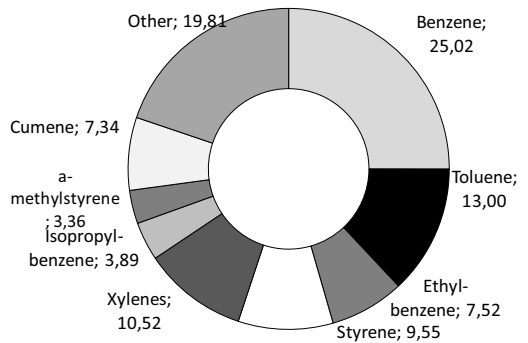

C-3

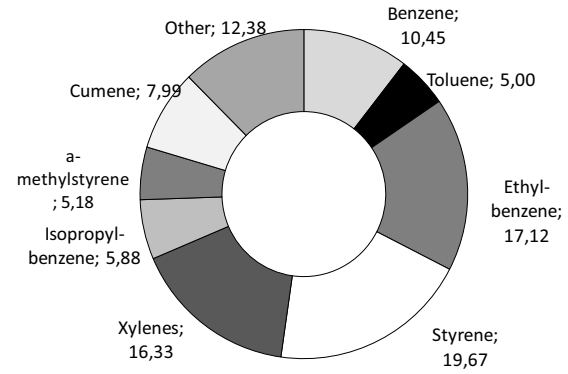

C-4

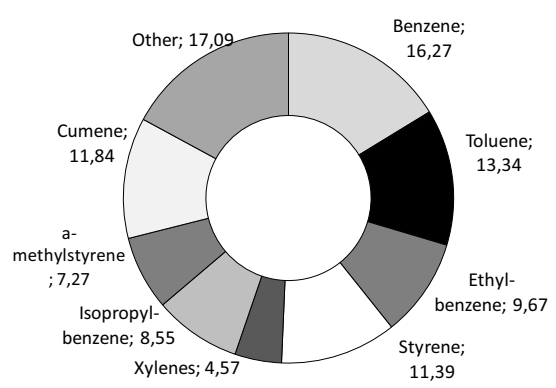

C-5

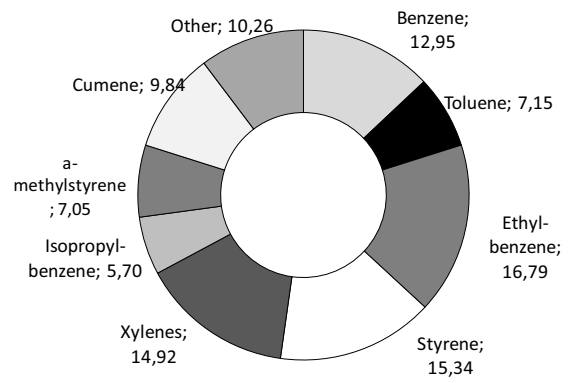

C-6

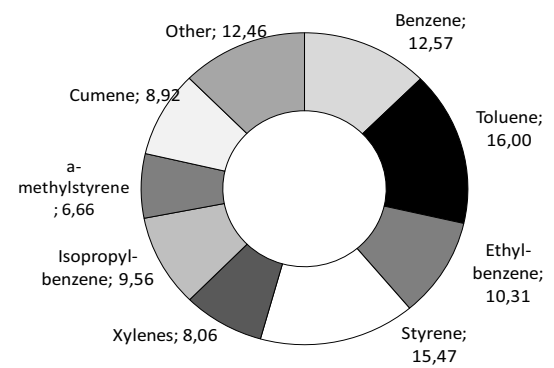

C-7

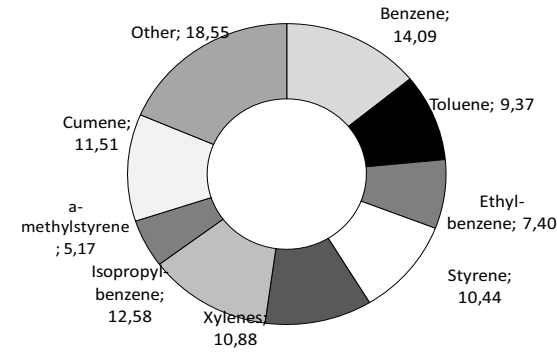

Figure 6. Composition of aromatics in pyrolysis oils.
It is an important observation, that the MCM-41 catalyst increases the concentration of benzene and toluene $(25.05 \%$ and $13.00 \%)$, while that of ethylbenzene, styrene and xylenes were lower $(7.52 \%, 9.55 \%$ and $10.52 \%$ ). This phenomenon could be attributed to the larger pore size and BET surface area of the MCM-41 catalyst, because those properties are favoured for the hydrogen transfer reactions and aromatization. That is why the aromatic side chain of aromatics could be further cracked which resulted in smaller molecules with shorter side chain. Furthermore also further decomposition of side chain if aromatics were found in the case of catalyst mixtures using MCM-41 catalyst (C-4, C-6).

As it was demonstrated in Table 1 , the raw material contained $0.05 \%$ chlorine and $0.02 \%$ sulphur, which should be transformed into compounds, which appeared in the pyrolysis oil fractions. Figure 7 demonstrates the concentrations of chlorine and sulphur in the pyrolysis oils. Without catalysts $257 \mathrm{ppm}$ chlorine and $125 \mathrm{ppm}$ sulphur were measured, which could be decreased using catalysts. Regarding chlorine, the MCM-41 catalyst had the highest activity in decreasing, because the $\mathrm{Cl}$ concentration was122ppm. Activated carbon had shown only a slight effect to the volatile product increasing and modifying the pyrolysis oil composition; however it has a significant effect in the case of sulphur content. Pyrolysis oil obtained by the degradation over activated carbon contained only $31 \mathrm{ppm}$ sulphur, which is a dominant decrease. On the other hand the two other catalysts only slightly could decrease the S content; 79ppm and 81ppm using MCM-41 and HZSM-5 catalysts. Presumably the large BET surface area was the cause for both $\mathrm{Cl}$ and $\mathrm{S}$ decreasing in the case of MCM-41 and activated carbon. According to Table 1, activated carbon had $859 \mathrm{~m}^{2} / \mathrm{g}$, while MCM-41 catalyst $824 \mathrm{~m}^{2} / \mathrm{g}$ BET surface area. Therefore possibly physical sorption was the cause for both $\mathrm{Cl}$ and $\mathrm{S}$ decreasing.

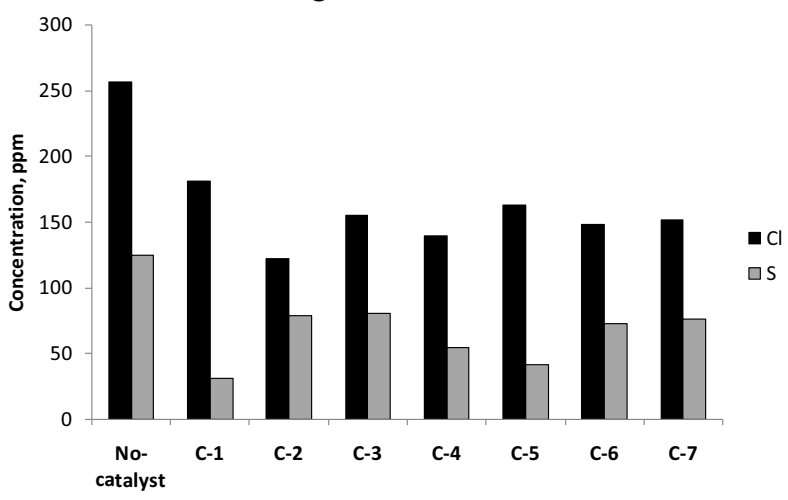

Figure 7. Chlorine and sulphur content of pyrolysis oils.

Volatile characteristic of pyrolysis oils was also followed by Engler distillation test. Figure 8 summarizes the distillation curves. The data well demonstrates, that pyrolysis oil obtained by catalyst free experiment contain nearly half of diesel oil range and 25\%-25\% kerosene and naphtha range hydrocarbons. In the presence of catalysts (especially HZSM-5) the portions of naphtha-like and kerosene-like hydrocarbons were higher, e.g. using HZSM-5 they were nearly $60 \%$ and $25 \%$, respectively. It 
was confirmed by earlier work, because it was demonstrated that owing to the small pore size, the HZSM-5 catalyst results especially hydrocarbons in naphtha boiling point range $\left(\mathrm{Bp}\right.$ below $\left.180^{\circ} \mathrm{C}\right)[10,11,16]$.

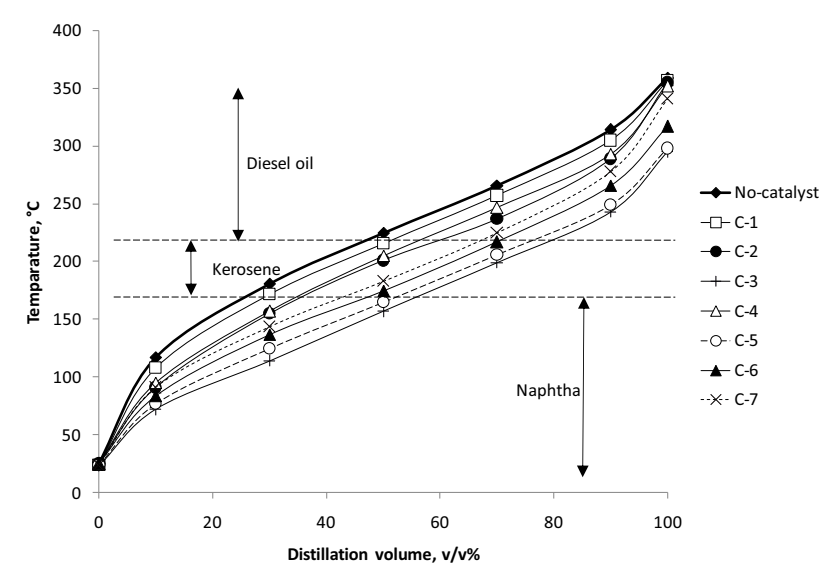

Figure 8. Engler distillation curves of pyrolysis oils.

Activated carbon had only a slight effect on the boiling point range, because the temperatures belong to specific distillation volumes, was only slightly lower than that without catalyst. MCM-41 catalyst could also slightly affect the boiling points, but its effect was most notable than in the case of activated carbon. Regarding catalyst mixtures, it was concluded, that especially the HZSM-5 containing mixtures (C-5, C-6 and C-7) could significantly increase the yield of naphtha or kerosene and decrease the yield of diesel oil.

\section{Conclusion}

The yields of gaseous product could be increased especially by HZSM-5 catalyst, while the yield of pyrolysis oil was increased both by HZSM-5 and MCM41 catalyts. Activated carbon had only a slight effect on the yields and hydrocarbons in the product. Significant isomerization effect was demonstrated both in the gases and pyrolysis oils using HZSM-5 catalyst and HZSM-5 catalyst containing catalyst mixtures. MCM-41 and HZSM-5 catalyst had also an aromatization effect, and the MCM-41 catalyst with larger pore size had activity in the formation of benzene and toluene. The most benefit of activated carbon was the enormous decrease in sulphur content, while the chlorine could be decreased especially by MCM-41 catalyst, which was attributed to its large pore surface area. Volatile characteristic of pyrolysis oils demonstrated the increase of the naphtha-like fraction content of pyrolysis oil using HZSM-5 catalyst.

\section{Acknowledgment}

The authors acknowledge the Horizon 2020, Marie Curie Research and Innovation Staff Exchange (RISE) (MSCARISE-2014 (Flexi-pyrocat, No.: 643322)).

\section{References}

1. H. T. Lin, M. S. Huang, J. W. Luo, L. H. Lin, C. M. Lee, and K. L. Ou, Fuel Processing Technology, 91, 1355 (2010)

2. E. V. Antonakou, K. G. Kalogiannis, S. D. Stefanidis, S. A. Karakoulia, K. S. Triantafyllidis, A. A. Lappas, and D. S. Achilias, Polymer Degradation and Stability, 110, 482 (2014)

3. Y. H. Lin, M. H. Yang, Journal of Molecular Catalysis A: Chemical, 231, 113 (2005)

4. G. Elordi, M. Olazar, M. Artetxe, P. Castano, and J. Bilbao, Applied Catalysis A: General, 415-416, 8995 (2012)

5. Y. H. Lin, H. Y. Yen, Polymer Degradation and Stability, 89, 101 (2005)

6. W. C. Huang, M. S. Huang, C. F. Huang, C. C Chen, K. L. Ou, Fuel, 89, 2305 (2010)

7. S. S. Kima, S. Kim, Chemical Engineering Journal, 98, 53 (2004)

8. N. S. Akpanudoh, K. Gobin, G. Manos, Journal of Molecular Catalysis A: Chemical, 235, 67 (2005)

9. X. Yang, L. Sun, J. Xiang, S. Hu, and S. Su, Waste Management 33 (2013), p. 462

10. J. F. Mastral, C. Berrueco, M. Gea, J. Ceamanos, Polymer Degradation and Stability, 91, 3330 (2006)

11. X. Zhang, H. Lei, G. Yadavalli, L. Zhu, Y. Wei, Y. Liu, Fuel, 144, 33 (2015)

12. J. Bozi, M. Blazsó, Journal of Analytical and Applied Pyrolysis, 97, 189 (2012)

13. W. L. Fanchiang, Y. C. Lin, Applied Catalysis A: General, 419-420, 419 (2012)

14. R. A. García, D. P. Serrano, D. Otero, Journal of Analytical and Applied Pyrolysis, 74, 379 (2005)

15. M. R. Jan, J. Shah, H. Gulab, Fuel, 105, 595 (2013)

16. A. López, I. Marco, B. M. Caballero, M. F. Laresgoiti, A. Adrados, and A. Aranzabal, Applied Catalysis B: Environmental, 104, 211 (2011)

17. K. H. Lee, Polymer Degradation and Stability, 93, 1284 (2008) 